\title{
La protección del accionista minoritario en las Sociedades Anónimas Abiertas
}

Alonso Morales Acosta

\section{Competencia del Comité}

\subsection{Aspectos Generales:}

La Ley No 26985 titulada "Ley de Protección a los Accionistas Minoritarios de las Sociedades Anónimas Abiertas" regula la actuación de las sociedades anónimas abiertas, señaladas en la Ley General de Sociedades - Ley No 26887 (en adelante LGS), respecto de ciertos derechos de los accionistas minoritarios.

En ese orden de ideas, la LGS, en su Art. $249^{\circ}$, se refiere a las sociedades anónimas, calificándolas como abiertas, por reunir una o más de las siguientes condiciones:

«1. Ha hecho oferta pública primaria de acciones u obligaciones convertibles en acciones;

2. Tiene más de setecientos cincuenta accionistas;

3. Más del treinta y cinco por ciento de su capital pertenece a ciento setenta y cinco o más accionistas, sin considerar dentro de este número aquellos accionistas cuya tenencia accionaria individual no alcance al dos por mil del capital o exceda del cinco por ciento del capital;

4. Se constituya como tal; o

5. Todos los accionistas con derecho a voto aprueban por unanimidad la adaptación a dicho régimen»

La doctrina sintetiza mejor estas características al definir su concepto de la siguiente manera: 
«La Sociedad Anónima Abierta al público -que, como veremos, no es más que un mecanismo jurídico emisor de títulos negociables- es una institución jurídico-pública, instituida por ley, para recoger el ahorro, con vistas a la explotación de las empresas, y una forma social de la organización económica... ${ }^{1}$

Los accionistas minoritarios son descritos por la ley como aquellos que no tienen acceso al ejercicio de los derechos derivados de sus acciones, dado que desconocen de su titularidad (por falta de información) ${ }^{2}$ o por que la Sociedad Anónima Abierta (en adelante la S.A.A.) $)^{3}$ no se las reconoce.

Es decir, se pretende informar (a través de publicaciones que es la razón principal de la Ley $N^{\circ} 26985$ ) que existen personas naturales o jurídicas titulares de acciones o dividendos de S.A.A. que no están ejerciendo sus derechos (probablemente por desconocimiento de los mismos). Asimismo, se establece un procedimiento en sede administrativa para resolver los reclamos de los que se consideran titulares de las acciones o dividendos dinerarios y que, en base a una decisión aparentemente arbitraria de la S.A.A., se les desconoce dichos derechos o dividendos dinerarios («denegatoria de la entrega de sus títulos y/o dividendos").

Vale decir, se regula un aspecto parcial de los derechos que conciernen a los accionistas minoritarios: los relacionados con la información sobre la existencia de sus derechos, el reconocimiento de los mismos y un debido procedimiento administrativo para canalizar los reclamos. ${ }^{4}$

1 Ngo Bà Thành citado por Enrique Elías Laroza en Ley General de Sociedades Comentada, Trujillo. Ed. Normas Legales S.A., 1999; p. 509.

2 El inciso 2.3. del artículo $2^{\circ}$ de la Ley No 26985 señala: «[...] La Sociedad procederá a publicar [...] el listado de accionistas que no hubieren reclamado sus títulos representativos de acciones y/o de aquellos que no hubieren cobrado sus dividendos".

3 El inciso 7.1. del artículo $7^{\circ}$ de la Ley No 26985 indica: "El solicitante al que se le hubiere denegado la entrega de sus títulos representativos de acciones y/o dividendos, de modo expreso o ficto, podrá reclamar este hecho ante la CONASEV".

4 La Ley No 26985 no trata de otros derechos como: derecho de información sobre asuntos a tratar en Junta General y otros aspectos societarios, aplazamiento de la Junta General, elección del directorio por voto acumulativo, convocatoria a Junta General solicitada por acciones que representen al menos el $5 \%$ del capital social, derecho de separación, distribución mínima de dividendos, entre otros, de conformidad con los arts. $130^{\circ}, 131^{\circ}$, $200^{\circ}, 231^{\circ}, 255^{\circ}, 261^{\circ}$ y $385^{\circ}$. 
De otro lado, es menester precisar que las acciones en general pueden ser representadas mediante certificados provisionales o definitivos y anotaciones en cuenta. Los certificados de acciones se caracterizan por su representación en hojas de papel. Vale decir, se trata de documentos de papel actualmente regulados entre otras disposiciones por los arts. $84^{\circ}, 87^{\circ}, 92^{\circ}$ y $100^{\circ}$ de la LGS. Asimismo son considerados como títulos nominativos según los arts. $29^{\circ}$ al $32^{\circ}$ de la Ley de Títulos Valores vigente (Ley No 16587).

Las anotaciones en cuenta representan valores desmaterializados tal como lo define el Art. $2^{\circ}$ del proyecto de ley de Títulos Valores ${ }^{5}$ y tal como se hallan reguladas en los arts. $209^{\circ}$ al $217^{\circ}$ de la Ley del Mercado de Valores (Decreto Legislativo No 861 ). En otros términos, las acciones no constan exclusivamente en documentos de papel sino también en documentos electrónicos.

Su registro y contabilización se efectúa a través de una institución de Compensación y Liquidación de Valores- ICLV (como CAVALI), bajo el recurso técnico de las «anotaciones en cuenta». El registro tendrá una función equivalente a la matrícula de acciones representadas mediante certificados (de papel) y las constancias de las anotaciones efectuadas en el registro equivaldrán a los certificados de acciones (de papel) provisionales o definitivos. ${ }^{6}$

5 Texto publicado por el diario oficial «El Peruano» el 3 de noviembre de 1999.

6 No debe llevar a confusión la referencia de certificados provisionales o definitivos, valores materializados en papel, con las constancias derivadas de los registros de anotaciones en cuenta, aún cuando éstas constancias son también denominadas por la Ley del Mercado de Valores como ucertificados". (Véase el artículo $216^{\circ}$ Ley del Mercado de Valores - Decreto Legislativo No 861).

Art. 216 .- Certificado.- La titularidad para la transmisión y el ejercicio de los derechos derivados de los valores representados por anotaciones en cuenta o de los derechos limitados o gravámenes constituidos sobre ellos pueden ser acreditados con certificado otorgado por la correspondiente institución de compensación y liquidación de valores, indicando la finalidad para la cual fue expedido y su plazo de vigencia.

El certificado a que se refiere el párrafo anterior no confiere más derecho que en los que en él se indica. El acto de disposición del certificado es nulo.

No puede expedirse más de un certificado para los mismos valores y para el ejercicio de los mismos derechos.

Es prohibido a las instituciones de compensación y liquidación de valores y a los miembros de los mercados de valores dar curso a transferencias o gravámenes, así como practicar las correspondientes inscripciones, en tanto el interesado no haya restituido los certificados expedidos a su favor, a menos que estos hubiesen caducado. 
No obstante lo mencionado, la LGS es categórica al indicar que sea cual fuere la representación de las acciones, estas confieren los mismos derechos a los accionistas

«Art. $84^{\circ}$ de la LGS.- [...] Los derechos que corresponden a las acciones emitidas son independientes de si ellas se encuentran representadas por certificados provisionales o definitivos, anotaciones en cuenta o en cualquier otra forma permitida por la Ley».

Como se puede apreciar no existe una diferencia de derechos que derive de la forma de representación.

\subsection{Problema}

La Ley No 26985 en armonía con la finalidad que hemos expuesto en el punto anterior, establece un procedimiento para efectuar publicaciones y reclamos por denegatoria de la entrega de «Títulos".

En la Ley se refiere constantemente a "títulos representativos de acciones», lo cual obviamente obliga a preguntarse qué debe entenderse por «títulos». Vale decir si se refiere a el: «origen, causa, razón o fundamento de un derecho $\mathrm{u}$ obligación o al documento materializado que prueba una relación jurídica, sea esta una deuda pública o un valor mercantil ${ }^{7}$.

Es vedad que existen argumentos en favor de ambas posiciones, pudiendo considerarse que el término "título" es un concepto abstracto y genérico, que invoca a la "acción" (como alícuota del capital social o aporte que confiere derechos políticos y económicos al socio), al margen de si su representación se traduce en un "certificado» o en una "anotación en cuenta".

No obstante lo mencionado, la consideración que se refiere sólo a título valor, vale decir a certificados provisionales o definitivos, hallaría sustento en las siguientes normas:

7 Guillermo Cabanellas, Diccionario Enciclopédico de Derecho Usual, Argentina. Ed. Heliasta, 1989, Tomo VIII, p. 103. 
1.- En la Ley del Mercado de Valores (D. Leg No 861) se alude al término "Título" como "Título Valor" reiteradamente y se le distingue de las anotaciones en cuenta, conforme puede apreciarse en los arts. $9^{\circ}$ inciso b), $80^{\circ}, 81^{\circ}, 103^{\circ}$ inciso i), $209^{\circ}$ segundo, tercero y cuarto párrafos, $213^{\circ}$ segundo párrafo, $214^{\circ}, 217^{\circ}$ segundo párrafo, $239^{\circ}, 250^{\circ}$ inciso a) y $253^{\circ}$ primer párrafo.

2.- En segundo término, en la Ley de Protección a los Accionistas Minoritarios de las Sociedades Anónimas Abiertas se alude reiteradamente a que la sociedad «entregará» los títulos representativos de acciones (inciso 3.1.y 3.2. del Art. $3^{\circ} \mathrm{y}$ el inciso 7.1. del Art. $7^{\circ} \mathrm{de}$ la Ley No $^{26985)}$ ), lo que alude a su aparente materialización en un documento de papel, puesto que sólo los «certificados» (título valor) son objeto de entrega por la sociedad.

En materia de anotaciones en cuenta la sociedad no entrega títulos sino, en todo caso, reconoce todos los derechos de los accionistas derivados del conjunto de acciones que se encuentran registradas en una institución de compensación y liquidación de valores (v. gr. CAVALI). En ese orden de ideas, la Resolución CONASEV No 038-99-EF/94.10, que no ha sido impugnada, optó por referirse a la «entrega de [...] certificados"; indicando, además, que bajo dicho término se comprende los certificados de acciones provisionales o definitivos, aludiendo con ello a la representación de acciones mediante documentos de papel de conformidad con el Art. $84^{\circ}$ de la LGS.

\subsection{Solución al problema}

Existen dos vías para solucionar este problema: una mediata (una ley); $y$, una inmediata (resolución complementaria del Directorio de CONASEV).

La primera sería una ley de precisión que obviamente tendría que pasar por un proceso de debate y aprobación en el Congreso de la República.

La segunda vía consiste en que el Directorio de CONASEV, al amparo del Art. $2^{\circ}$ incisos a) y b) y el Art. $11^{\circ}$ incisos b), m) y r) de la Ley Orgánica de la CONASEV (D. L. No 26126), así como de la Quinta Disposición Final de la Ley № 26985 (Ley de Protección al Accionista Minoritario en S. A. A. ), dicte normas complementarias 
para que se cumpla con una tutela efectiva del accionista minoritario, pues no existe un fundamento legítimo para diferenciar la protección por razón de la forma.

En efecto, la normatividad citada reconoce las siguientes prerrogativas y facultades:

Ley orgánica de la Comisión Nacional Supervisora de Empresas y Valores (D.L. No 26126):

"Art. 2.- Son funciones de la Comisión Nacional Supervisora de Empresas y Valores las siguientes:

a) Estudiar, promover y reglamentar el mercado de valores $y$ controlar a las personas naturales y jurídicas que intervienen en dicho mercado,

b) Supervisar a las personas jurídicas organizadas de acuerdo a la Ley General de Sociedades y a las sucursales de empresas extranjeras que se hallen dentro de los límites que la propia Comisión fije, así como a las cooperativas.

Art. $11^{\circ}$.- Son funciones y atribuciones del Directorio, además de las que se le asignan en la Ley del Mercado de Valores o en otras normas legales, las siguientes:

b) Dictar las normas que regulen las operaciones en el mercado de valores, así como aquéllas a que deben sujetarse las personas naturales o jurídicas sometidas al control y supervisión de CONASEV;

m) Aprobar el Reglamento de Organización y Funciones de la CONASEV, así como los demás reglamentos internos.

r) Establecer los procedimientos, con delegación de facultades y definición de instancias, para que se resuelva de manera expeditiva los asuntos de competencia de CONASEV.

Ley de protección a los accionistas minoritarios de las sociedades anónimas abiertas (Ley No 26985):

Quinta.- Expedición de normas complementarias por la CONASEV-

La CONASEV será el organismo encargado de dictar las normas complementarias que sean necesarias para la mejor aplicación de la presente ley."

En base a las normas citadas, se podrían aprobar normas complementarias que permitan una mejor aplicación de la Ley No 26985, 
cumpliendo con dar información suficiente y oportuna sobre la existencia de acciones representadas por Anotaciones en Cuenta, así como los dividendos derivados de estas acciones y que por desconocimiento no se pueden cobrar. De igual manera, se contemplaría el derecho de estos accionistas a reclamar por el desconocimiento injustificado o arbitrario de sus derechos sea por haberse brindado información deficiente o por negarse la Sociedad Anónima Abierta a instruir a la ICLV (CAVALI) para que corrija su registro y anote correctamente el nombre del titular.

\section{Procedimiento de «entrega» y «denegatoria» de títulos}

Los procedimientos que se están realizando actualmente para proteger al accionista minoritario conforme a la Ley No 26985 prácticamente no variarían, simplemente tienen que adecuarse a la realidad del sistema de anotaciones en cuenta.

En ese orden de ideas las etapas de los procedimientos descritos en la mencionada Ley se desarrollarían del modo siguiente:

1.- La Sociedad Anónima Abierta efectuará publicaciones en la que estará obligado a incluir los certificados o las anotaciones en cuenta representativas de títulos de acciones.

2.- Las personas que se consideran titulares de valores o dividendos procederán a acreditar sus derechos ante la Sociedad Agente relacionada para el efecto con la ICLV (CAVALI) correspondiente, lo cual en buena cuenta descongestionará las oficinas de la Sociedad Anónima Abierta.

3.- Al solicitante que se le haya negado los derechos sobre sus acciones (dado que no se le permite disponer de los mismos) podrá ante la Sociedad Anónima Abierta (el emisor) solicitar que se forme un expediente con los antecedentes y elevarlo a la CONASEV.

4.- La resolución expedida en base al reclamo formulado será igualmente notificada a la Sociedad Anónima Abierta, la que tendrá que indicar a CAVALI que corrija su registro mediante el cual se dio acceso a las anotaciones en cuenta.

Por ejemplo: si COPA determinó el cambio de nombre y la entrega de títulos de acciones en favor de una persona natural, obligará a 
la sociedad emisora a solicitar a la ICLV (CAVALI) que rectifique su registro, la cual procederá a efectuarlo por el simple requerimiento.

Cabe resaltar que también el cambio de titularidad podrá efectuarse directamente según lo previsto el Art. $58^{\circ}$ de la Resolución de CONASEV No 31-99-EF/94.10 (Reglamento de Instituciones de Compensación y Liquidación de Valores) el cual establece lo siguiente:

«Art. 58०.- Las ICLV, a solicitud del respectivo titular o interesado, o a través del participante, deben registrar el cambio de titularidad de los valores inscritos en el registro contable de forma inmediata, previa evaluación de la documentación necesaria para efectuar la respectiva inscripción, de acuerdo a lo que establezcan los Reglamentos Internos, cuando se trate de los supuestos contemplados en el Art. $11^{\circ}$ de la Resolución CONASEV No 027-95-EF/94.10.

Las ICLV deben difundir al mercado las normas que detallen la documentación necesaria para registrar el cambio de titularidad en los supuestos a que se refiere el párrafo precedente. "

Los supuestos a que se refiere la Resolución de CONASEV No 027-95-EF/94.10 se refieren fundamentalmente a los casos de herencia, anticipo de herencia, división y partición de masa hereditaria, donación, separación de patrimonios en una sociedad conyugal, fusión y escisión de sociedades; fusión de fondos de pensiones, fusión de fondos mutuos de inversión en valores y fondos de inversión, así como otros que resuelva favorablemente CONASEV (como las resoluciones de COPA).

Como puede apreciarse, hasta este punto, no existe mayor diferencia en el procedimiento que se ha venido siguiendo ante esta institución. Empero, si se trata de casos en los cuales la Sociedad Anónima Abierta entregó acciones por error o fraude a terceros, tendrá que cumplir con el verdadero titular adquiriendo las acciones en el mercado de valores.

En conclusión, si bien no se aprecian mayores diferencias, será necesario que la COPA coordine y adecue su procedimiento con el fin que la norma complementaria (sobre anotaciones en cuenta) que se sugiere expedir armonice con la realidad. 
III Consecuencias para el accionista que no recoge sus dividendos ni sus acciones

Producto del desconocimiento los accionistas no sólo se encuentran limitados en el ejercicio de sus derechos políticos, sino que con el transcurso del tiempo pueden caducar sus derechos económicos y políticos.

En efecto, la LGS establece en su Art. $232^{\circ}$, tal como ha quedado modificado por la Ley $\mathrm{N}^{\circ} 26985$, que:

«El derecho a cobrar el dividendo caduca a los tres años, a partir de la fecha en que su pago era exigible conforme al acuerdo de declaración del dividendo.

Sólo en el caso de las Sociedades Anónimas Abiertas, el plazo de caducidad a que se refiere el párrafo precedente será de diez años»

Como puede apreciarse el término de caducidad de los dividendos que corresponden al accionista para reclamar sus dividendos en una Sociedad Anónima Abierta es de diez años.

Cabe precisar que aún cuando el término «dividendo» no se ha definido directamente en la ley, se puede deducir de una interpretación sistemática de los arts. $107^{\circ}$ (segundo párrafo) y $231^{\circ}$ de la LGS que su concepto comprende tanto el pago en dinero como en acciones (acciones liberadas), según puede verificarse a continuación:

«Art. 107\%.- Usufructo de acciones:

[...] Puede pactarse que también correspondan al usufructuario los dividendos pagados en acciones de propia emisión que toquen al propietario durante el plazo del usufructo.

Art. 231\%.- Dividendo obligatorio:

Es obligatoria la distribución de dividendos en dinero hasta por un monto igual a la mitad de la utilidad distribuible de cada ejercicio, luego de detraído el monto que debe aplicarse a la reserva legal, si así lo solicitan accionistas que representen cuando menos el veinte por ciento del total de las acciones suscritas con derecho a voto. Esta solicitud sólo puede referirse a las utilidades del ejercicio económico inmediato anterior.

El derecho de solicitar el referido reparto de dividendos no puede 
ser ejercido por los titulares de acciones que estén sujetas a régimen especial sobre dividendos"

Cabe preguntarnos si la caducidad alcanza a los dos tipos de dividendos tanto al dinerario como a las acciones liberadas. En nuestra opinión sólo cabe la caducidad respecto de los dividendos dinerarios; puesto que sólo estos se encuentran pendientes de cobro.

En efecto, cuando se acuerda la distribución de dividendos dinerarios, la sociedad reconoce un crédito a favor del accionista. Este tiene que efectuar su cobro para tener a su disposición el importe correspondiente a dichos dividendos.

En cambio, las acciones liberadas son reconocidas por la sociedad mediante su inscripción en la matrícula de acciones, la cual justamente acredita la propiedad de las mismas (Art. 910 de LGS). Según la legislación societaria la posesión de los títulos emitidos a nombre de una persona constituye un medio probatorio de propiedad, pero la prueba fundamental y definitiva es la que se sustenta en la matrícula de acciones.

En buena cuenta, la sociedad al emitir acciones y registrarlas en la matrícula correspondiente ha reconocido los derechos inherentes al accionista y por ende su titularidad (al margen que proceda o no a emitir los títulos); salvo resolución judicial en sentido distinto.

Los dividendos dinerarios al encontrarse pendientes de cobro pueden sufrir las consecuencias de la caducidad prevista en el Art. $232^{\circ} \mathrm{de}$ LGS, norma que sanciona de este modo al acreedor negligente.

La norma precisa además que estos recursos que figuran en el activo incrementan el patrimonio en la cuenta de la reserva legal, salvo que habiendo llegado ésta a su límite máximo se proceda a su capitalización o a su redistribución.

" [...) Nótese que si la reserva legal estuviese en su límite máximo, esos montos no tendrían la condición de reserva legal, a tenor del artículo $229^{\circ}$, por lo que, en ese caso, procede su capitalización o redistribución". ${ }^{8}$

8 Enrique Elías Laroza Ley General de Sociedades Comentada, Trujillo. Ed. Normas Legales S.A.; p. 490. 


\section{Las sanciones por incumplimiento}

La Ley de Protección al Accionista Minoritario contempla sanciones muy rigurosas para la Sociedad Anónima Abierta que no cumple con los procedimientos y disposiciones establecidas. Estas consisten fundamentalmente en multas no menores de 50 UIT ni mayores de 100 UIT. $^{9}$

Estas sanciones pueden ser excesivamente draconianas con la Sociedad Anónima Abierta que ha efectuado el procedimiento defectuosamente, aun cuando se halla cumplido con la finalidad de la Ley No 26985. Ejemplos de lo mencionado pueden ser los siguientes: retrasos en las publicaciones uno o dos días de transcurrido el plazo de ley, no incluir en la cuarta publicación a todos los accionistas subsanando dicho hecho inmediatamente o por omitir indicar los gastos de difusión regularizando dicho acto en fecha posterior.

No obstante lo mencionado, si el COPA tuviera que sancionar algunos de los actos o conductas mencionadas tendría poco margen para su discrecionalidad, dado que los extremos entre los cuales oscilarían las multas son elevados. En todo caso, el legislador tiene la palabra sobre una mayor flexibilidad del COPA en el ejercicio del poder punitivo.

\section{CONGRESO DE LA REPÚBLICA}

LEY No 26985

\section{LEY DE PROTECCIÓN A LOS ACCIONISTAS MINORITA- RIOS DE LAS SOCIEDADES ANÓNIMAS ABIERTAS}

Artículo $1^{\circ}$.- Ámbito de aplicación

La presente ley será de aplicación a las Sociedades Anónimas Abiertas, en adelante Sociedad o Sociedades, reguladas por la Ley No 26887 - Ley General de Sociedades.

9 De acuerdo a la escala vigente, la UIT tiene un valor de $S / .2,900.00$ (dos mil novecientos y 00/100 nuevos soles). En tal sentido 50 UIT es equivalente a S/. 145,000.00 (ciento cuarenta y cinco mil y 00/100 Nuevos Soles) y 100 UIT es igual a S/. :90,000.00 (doscientos noventa mil y 00/100 Nuevos Soles). 


\section{CAPÍTULO I}

\section{DEL PROCEDIMIENTO DE PROTECCIÓN}

Artículo $2^{\circ}$.- Procedimiento de protección de accionistas minoritarios

2.1. La Sociedad, a fin de proteger efectivamente los derechos de los accionistas minoritarios, deberá publicar en un plazo que no excederá de los 60 (sesenta) días de realizada la Junta Obligatoria Anual a que se refiere el Artículo $114^{\circ}$ de la Ley No 26887 -Ley General de Sociedades-, el número total de los títulos representativos de acciones no reclamados y el valor total de los mismos, según la cotización vigente en el mercado de valores a la fecha que se remite el aviso a los medios de comunicación. Asimismo, la Sociedad publicará el monto total de los dividendos no cobrados y exigibles conforme al acuerdo de declaración de dividendos indicando el lugar donde se encuentran los listados con información detallada, así como el lugar y el horario de atención para que los accionistas minoritarios puedan reclamar sus títulos representativos de acciones y/o cobrar sus dividendos.

2.2. La publicación se efectuará en el Diario Oficial y en otro de circulación nacional, cada 30 (treinta) días por 3 (tres) meses consecutivos, actualizando la información correspondiente. A criterio de la Sociedad, adicionalmente, podrán utilizarse otros medios de difusión masiva.

2.3. Transcurridos 30 (treinta) días contados a partir de la última publicación, la Sociedad procederá a publicar por los mismos medios señalados en el numeral precedente, el listado de accionistas que no hubieren reclamado sus títulos representativos de acciones y/o de aquellos que no hubieren cobrado sus dividendos. Asimismo, se publicará el monto de los gastos de difusión en que hubiese incurrido la Sociedad como consecuencia del procedimiento de protección de los accionistas minoritarios; con lo que concluirá dicho procedimiento, sin perjuicio del análisis que efectuará la Comisión Nacional Supervisora de empresas y Valores -CONASEV-.

Artículo $3^{\circ}$.- Solicitud de entrega de los títulos representativos de acciones y/o dividendos.

3.1. Los interesados deberán acudir al local de la Sociedad designado para estos efectos, para solicitar la entrega de los títulos represen- 
tativos de sus acciones y/o los dividendos. Para tal fin, deberán presentar los siguientes documentos según se trate de personas naturales o jurídicas:

a) Documento de identidad, adjuntando copia de la misma.

b) Los poderes que acrediten al representación del titular, de ser el caso.

c) Documentos que acrediten la condición de heredero o legatario, de ser el caso.

d) Documentos que acrediten al titularidad de las acciones, cuando corresponda.

3.2. Con la presentación de los documentos a que hubiere lugar, señalados en el presente artículo, la Sociedad entregará los títulos representativos de acciones y/o los dividendos en un plazo de 30 (treinta) días. Vencido dicho plazo sin que exista un pronunciamiento de la Sociedad, se entenderá denegada la solicitud, quedando expedito el procedimiento administrativo de solución de controversias a que se refiere el Capítulo II de la presente ley.

Artículo 4º.- Supervisión de la CONASEV.

La Sociedad dentro de los 60 (sesenta) días siguientes $\cdot d e$ efectuada la última publicación a que se refiere el párrafo 2.3 del Artículo $2^{\circ}$ de la presente ley, remitirá a la CONASEV lo siguiente:

a) Copias de las publicaciones establecidas en el Artículo $2^{\circ}$ de la presente ley;

b) El listado de aquellos accionistas que hubieran procedido a reclamar sus títulos representativos de acciones y/o cobrar sus dividendos;

c) El listado de accionistas que no hubiesen reclamado sus títulos representativos de acciones y/o dividendos.

Artículo $5^{\circ}$.- Del análisis y certificación.

La CONASEV analizará la documentación recibida a que se refiere el Artículo $4^{\circ}$ y si es conforme expedirá el correspondiente certificado que acredite que la Sociedad cumplió con el procedimiento señalado en la presente ley. 
Artículo 60.- Gastos de Difusión.

Los gastos de difusión derivados del procedimiento de protección a los accionistas minoritarios previstos en la presente ley, serán de cargo de la Sociedad, la que podrá deducirlos proporcionalmente de los dividendos no cobrados que hubieran dado origen al inicio de dicho procedimiento.

\section{CAPÍTULO II \\ DE LA SOLUCIÓN DE CONTROVERSIAS}

Artículo $7^{\circ}$.- Procedimiento de Reclamación.

7.1. El solicitante al que se le hubiere denegado la entrega de sus títulos representativos de acciones y/o dividendos, de modo expreso o ficto, podrá reclamar este hecho ante la CONASEV.

7.2. El reclamo se presentará ante la Sociedad respectiva, en un plazo de 15 (quince) días hábiles contados a partir de la notificación de la denegatoria de la Sociedad o de la denegatoria ficta. El expediente será elevado a la CONASEV, con los documentos necesarios para resolver que obren en poder de la Sociedad, en el término de 3 (tres) días hábiles. La CONASEV deberá resolver el reclamo dentro de los 30 (treinta) días hábiles contados desde que fueren recibidos los documentos remitidos por la Sociedad, sin más trámite que el análisis de los mismos. Dentro de este plazo, la CONASEV podrá solicitar cualquier documento adicional al interesado.

Artículo $8^{\circ}$.- Efectos de la Resolución de la CONASEV.

8.1. Notificada la Resolución de CONASEV, ésta podrá ser objeto de acción contencioso administrativa, en un plazo de 15 (quince) días hábiles. En el caso de ser declarado fundado el reclamo, la resolución tendrá carácter suspensivo.

8.2. Transcurrido el plazo a que se refiere el numeral precedente, sin ser impugnada la Resolución Administrativa de CONASEV, ésta quedará firme. De ser el caso, el accionista se apersonará a la Sociedad con la copia de dicha resolución, a fin de que ésta proceda a la entrega de los títulos representativos de acciones o los dividendos, en un plazo que no excederá de los 15 (quince) días de presentada. 
Artículo 90.- Sanciones.

En caso que la Sociedad incumpla con lo dispuesto en la presente ley, la CONASEV aplicará una sanción administrativa no menor de 50, ni mayor de 100 Unidades Impositivas Tributarias (UIT).

\section{DISPOSICIONES FINALES}

Primera.- Modificación del Artículo 232 $2^{\circ}$ de la Ley No 26887.

Modifícase el Artículo 232 $2^{\circ}$ de la Ley No 26887 -Ley General de Sociedades-, en los términos siguientes:

"Artículo 2320.- Caducidad del cobro de dividendos.

El derecho a cobrar el dividendo, caduca a los tres años, a partir de la fecha en que su pago era exigible conforme al acuerdo de declaración del dividendo.

Sólo en el caso de las Sociedades Anónimas Abiertas, el plazo de caducidad a que se refiere el párrafo precedente será de diez años.

Los dividendos cuya cobranza haya caducado incrementan la reserva legal".

Segunda.- Devolución de los Títulos Representativos de Acciones y de los Dividendos.

El Banco de la Nación devolverá a las Sociedades, en un plazo que no excederá de 3 (tres) días hábiles de la entrada en vigencia de la presente ley, los títulos representativos de acciones y los dividendos no cobrados que hubieran sido depositados por las empresas o sociedades, en el Fondo de Fideicomiso dispuesto por el Decreto de Urgencia No 106-97. La devolución de los dividendos no cobrados incluirá los intereses devengados por éstos.

Tercera.- Derogatorias.

Deróganse la Primera y Segunda Disposiciones Finales de la Ley No 26923 y el Decreto de Urgencia No 106-97.

Cuarta.- Aplicación inmediata de la norma.

Las Sociedades adecuadas o no a la Ley No 26887, que hubieren estado comprendidas dentro de los alcances del Decreto de Urgencia No 106-97, deberán iniciar la entrega de los títulos representativos de acciones no reclamadas o dividendos no cobrados, a partir del $7^{\circ}$ día hábil de la entrada en vigencia de la presente ley. 
Por única vez, dentro del plazo máximo de 30 (treinta) días hábiles de la entrada en vigencia de la presente ley, las Sociedades darán inicio al procedimiento de protección de accionistas minoritarios, sin la realización de la Junta Obligatoria Anual a que hace referencia el numeral 2.1 del Artículo $2^{\circ}$ de esta norma.

En caso de incumplimiento de lo dispuesto en el presente artículo se impondrá la sanción pecuniaria a que se refiere el Artículo $9^{\circ}$ de la presente ley.

Quinta.- Expedición de normas complementarias por la CONASEV.

La CONASEV será el organismo encargado de dictar las normas complementarias que sean necesarias para la mejor aplicación de la presente ley.

Comuníquese al señor Presidente de la República para su promulgación.

En Lima, a los veintitrés días del mes de octubre de mil novecientos noventa y ocho.

VICTOR JOY WAY ROJAS

Presidente del Congreso de la República

CARLOS BLANCO OROPEZA

Segundo Vicepresidente del Congreso de la República

AL SEÑOR PRESIDENTE CONSTITUCIONAL DE LA REPUBLICA

\section{POR TANTO:}

Mando se publique y cumpla.

Dado en la Casa de Gobierno, en Lima, a los veintiocho días del mes de octubre de mil novecientos noventa y ocho.

RICARDO MáRQUEZ FLORES

Vicepresidente de la República

Encargado del Despacho Presidencial

ALBERTO PANDOLFI ARBULú

Presidente del Consejo de Ministros

Encargado de la Cartera de Economía y Finanzas

ALFREDO QUISPE CORREA

Ministro de Justicia 
RESOLUCION CONASEV

No 038-99-EF/94.10

Lima, 9 de marzo de 1999

VISTOS:

El Memorándum No 028-99-EF/94.COPA de fecha 25 de febrero de 1999 y el Acuerdo No 24-99 del Comité de Protección al Accionista Minoritario adoptado en la sesión del Comité de fecha 25 de febrero de 1999;

\section{CONSIDERANDO:}

Que, la Ley No 26985, Ley de Protección a los Accionistas Minoritarios de las Sociedades Anónimas Abiertas, publicada en el Diario Oficial el 29 de octubre de 1998, encarga a la Comisión Nacional Supervisora de Empresas y Valores, CONASEV, conocer y resolver los reclamos que presenten los solicitantes a los cuales se les hubiere denegado de modo expreso o ficto la entrega de sus títulos representativos de acciones y/o dividendos en las sociedades anónimas abiertas, así como la supervisión del procedimiento de protección;

Que, mediante Resolución CONASEV No 164-98-EF/94.10 publicada en el Diario Oficial el 24 de diciembre de 1998, se crea el Comité de Protección al Accionista Minoritario como órgano de CONASEV, encargándosele las funciones que le fueren asignadas por la Ley No 26985;

Que, asimismo, mediante la Resolución CONASEV No 025-99EF/94.10 publicada en el Diario Oficial el 14 de febrero de 1999, se precisa que el Comité de Protección al Accionista Minoritario es el encargado de conocer y resolver, en instancia administrativa única, los reclamos que presenten los solicitantes a que se refiere el primer considerando;

Que, la Quinta Disposición Final de la Ley No 26985 dispone que esta Comisión Nacional dicte las normas complementarias que sean necesarias para una mejor aplicación de la referida ley; 
Estando a lo establecido en el inciso a) del artículo $2^{\circ}$ del Texto Unico Concordado de la Ley Orgánica de la Comisión Nacional Supervisora de Empresas y Valores aprobado por Decreto Ley No 26126, el artículo $249^{\circ}$ y siguientes de la Ley General de Sociedades aprobada por Ley No 26887, la Quinta Disposición Final de la Ley No 26985, así como a lo acordado por el Directorio de esta Comisión Nacional en la sesión de 8 de marzo de 1999.

\section{SE RESUELVE:}

Artículo 10.- Aprobar las Normas Complementarias Procedimentales de la Ley de Protección a los Accionistas Minoritarios de las Sociedades Anónimas Abiertas, Ley No 26985, que se adjuntan como anexo a la presente resolución.

Artículo $2^{\circ}$.- La presente Resolución rige a partir del día siguiente de su publicación.

Regístrese, comuníquese y publíquese,

Enrique Díaz Ortega

PRESIDENTE

Comisión Nacional Supervisora de Empresas y Valores.

NORMAS COMPLEMENTARIAS PROCEDIMENTALES A LA LEY DE PROTECCION A LOS ACCIONISTAS MINORITARIOS DE LAS SOCIEDADES ANÓNIMAS ABIERTAS, LEY N²6985

\section{TÍTULO I}

\section{DISPOSICIONES GENERALES}

Artículo $1^{\circ}$.- Del Comité

El Comité de Protección al Accionista Minoritario está encargado de conocer y resolver las reclamaciones de los interesados a los cuales se les hubiere denegado de manera expresa o ficta, la entrega de sus certificados de acciones y/o dividendos.

Asimismo, le corresponde supervisar el cumplimiento efectivo del proceso de protección de accionistas por parte de las sociedades anó- 
nimas abiertas.

Artículo $2^{\circ}$.- Términos

Los términos que se indican tienen el siguiente alcance en las presentes normas:

a) Accionista: Accionista minoritario de las sociedades anónimas abiertas.

b) Certificados de acciones: Certificados de acciones sean provisionales o definitivos.

c) CONASEV: Comisión Nacional Supervisora de Empresas y Valores.

d) Comité: Comité de Protección al Accionista Minoritario de CONASEV.

e) Ley: Ley de Protección a los Accionistas Minoritarios de las Sociedades Anónimas Abiertas, Ley $\mathrm{N}^{\circ} 26985$.

f) Ley de Procedimientos Administrativos: Texto Único Ordenado de la Ley de Normas Generales de Procedimientos Administrativos aprobado por Decreto Supremo $\mathrm{N}^{\circ}$ 02-94-JUS.

g) Sociedad: Sociedad anónima abierta. Comprende también a las que al cierre del ejercicio anual cumpla con cualquiera de las condiciones establecidas en los numerales 1, 2 y 3 del artículo 249 de la Ley General de Sociedades, Ley $N^{\circ} 26887$, independientemente de si se ha adaptado al régimen de tales sociedades conforme al segundo párrafo del artículo 263 de la misma Ley.

\section{TÍTULO II}

\section{TRÁMITE ANTE LA SOCIEDAD}

Artículo $3^{\circ}$.- Requisitos de la solicitud

Los requisitos generales para solicitar a la sociedad la entrega de los certificados de acciones y/o dividendos son los siguientes:

A. Personas Naturales:

A.1. A.2. A.3. A.4. A.5. Solicitud verbal o en el formato proporcionado por la sociedad, sin perjuicio del supuesto comprendido en el 
segundo párrafo del artículo siete. Original del documento de identidad del recurrente y copia simple del mismo. El original se devolverá en forma inmediata después de la presentación del mismo. Poder suficiente que acredite la representación del titular, de ser el caso. Documento que acredite la condición de heredero o legatario del titular. Documentos que acrediten el derecho que se solicita en los casos que el recurrente cuente con los mismos, y a falta de ellos los documentos que estime pertinentes para tal efecto.

\section{B. Personas Jurídicas:}

B.1. B.2. B.3. B.4. B.5. Solicitud por escrito con firma del representante legal o presentada en el Formato Único del Colegio de Notarios del domicilio del solicitante. Original del documento de identidad del representante y copia simple del mismo. El original se devolverá en forma inmediata después de la presentación del mismo. Poder en el cual conste las facultades del representante legal con los datos de inscripción en el Registro Público del domicilio social de la persona jurídica solicitante. Certificado de vigencia del poder del representante expedido por el Gerente General de la persona jurídica solicitante. Documentos que acrediten el derecho que se solicita en los casos que el recurrente cuente con los mismos, y a falta de ellos los documentos que estime pertinentes para tal efecto.

\section{Artículo $4^{\circ}$.- Documentación adicional}

Excepcionalmente y mediante decisión motivada, la sociedad, por escrito, podrá solicitar documentación adicional a la referida en el artículo tercero, si la documentación inicialmente presentada no genera convicción sobre la identidad del solicitante.

Artículo $5^{\circ}$.- Firma de abogado

Para efectos de la Ley, no constituye requisito de admisibilidad de la solicitante ante la sociedad, reclamo o queja ante CONASEV, que la misma se encuentre autorizada por abogado.

Artículo $6^{\circ}$.- Poderes en documentos con firma legalizada

Los poderes extendidos fuera del domicilio de la sociedad mediante carta legalizada cuando corresponda de acuerdo a la cuantía, deberán 
ser autenticados por el Decano del Colegio de Notarios de la circunscripción correspondiente.

Artículo $7^{\circ}$.- Formatos de documentos

De conformidad a lo dispuesto por los artículos 33 y 35 de la Ley de Procedimientos Administrativos, el Comité establecerá los formatos impresos a ser utilizados por los recurrentes para las solicitudes y reclamos presentados ante la respectiva sociedad.

Asimismo, podrán ser atendidas las solicitudes y reclamos que no utilicen los referidos formatos siempre que contengan los elementos suficientes para emitir pronunciamiento.

\section{TITULO III}

DEL PROCESO ANTE EL COMITÉ

\section{Capítulo I}

\section{DE LA ELEVACIÓN DEL EXPEDIENTE}

Artículo $8^{\circ}$.- Formalidad de la elevación del reclamo

Interpuesto el reclamo ante la sociedad, ésta elevará obligatoriamente el expediente ante el Comité con un oficio de remisión, bajo responsabilidad. El expediente se remitirá debidamente foliado incluyendo el pronunciamiento motivado de la sociedad sobre la solicitud, con un informe debidamente suscrito, así como toda la documentación correspondiente.

En el supuesto de la denegatoria ficta, la sociedad deberá elevar el reclamo ante el Comité con un oficio de remisión, bajo responsabilidad. Asimismo, deberá acompañar toda la documentación respectiva que obre en poder de ella.

El oficio de elevación deberá identificar lo remitido, señalando el número de fojas con que cuenta el expediente.

Capítulo II

PLAZOS

Artículo $9^{\circ}$.- Plazo de contestación al requerimiento de información y/o documentación. 
Recibido el expediente, el Comité, de considerarlo necesario, podrá solicitar la información y/o documentación a la sociedad y/o al reclamante, quienes contarán con un plazo no mayor de diez (10) días hábiles para responder a dicho requerimiento.

Artículo $10^{\circ}$.- Plazo para la resolución

Recibido el expediente elevado por la sociedad, se inicia el plazo de treinta días hábiles expresado en el numeral 7.2 del artículo $7^{\circ}$ de la Ley para la resolución del reclamo. Excepcionalmente, en el caso que el Comité requiera información y/o documentación podrá suspender el plazo antes señalado.

\section{TITULO IV \\ DE LAS QUEJAS}

\section{Artículo $11^{\circ}$.- Procedencia de las Quejas}

El recurrente podrá interponer por escrito Queja de hecho ante el Comité, describiendo los hechos y fundamentando los motivos por los cuáles ésta deba ser atendida, en los siguientes casos:

1. Cuando la sociedad se niega a recibir la solicitud para el inicio del trámite de entrega de certificados de acciones y/o dividendos.

2. Cuando la sociedad se niega a recibir el reclamo al Comité una vez producida la denegatoria expresa o ficta.

3. Cuando la sociedad no cumpla con elevar a CONASEV, dentro del plazo señalado en la Ley, el expediente con el reclamo interpuesto por el solicitante.

Artículo $12^{\circ}$.- Trámite de la Queja

Una vez recibida la queja, la Secretaría Técnica del Comité correrá traslado a la sociedad en el plazo de dos (2) días hábiles a efectos que pueda presentar, en un plazo no mayor de tres (3) días hábiles, los descargos correspondientes. Una vez vencido dicho término y con la documentación con que se cuente, el Comité se pronunciará en el plazo de cinco (5) días hábiles. 
TÍTULO $\mathrm{V}$

\section{EJECUCIÓN DE LA RESOLUCIÓN}

Artículo $13^{\circ}$.- Ejecución de la Resolución emitida por el Comité Para solicitar la ejecución de la resolución emitida por el Comité, el solicitante deberá requerir por escrito a la sociedad la entrega de sus certificados de acciones y/o dividendos adjuntando, para tales efectos, copia de la resolución emitida por el Comité.

El plazo de quince (15) días hábiles con que cuenta la sociedad para la mencionada entrega, corre a partir de la presentación de la referida solicitud, bajo responsabilidad de la sociedad.

Artículo $14^{\circ}$.- Incumplimiento en la entrega del certificado de acciones $\mathrm{y} / \mathrm{o}$ dividendos

Cuando la sociedad no cumpla con la entrega de las acciones y/o dividendos según sea el caso, no obstante lo dispuesto por la Resolución del Comité, una vez vencido el plazo de quince (15) días hábiles de haber solicitado el accionista la referida entrega con la formalidad establecida en el artículo precedente, el solicitante informará este hecho ante el Comité.

\section{Disposiciones Finales}

\section{Primera.- Difusión}

La sociedad, luego de efectuada la publicación a que se refiere el punto 2.1 del artículo $2^{\circ}$ de la Ley, difundirá en el lugar que haya destinado para la entrega de certificados de acciones y/o dividendos, el procedimiento de la solicitud ante la sociedad, el derecho de reclamación en el caso de denegatoria expresa o ficta ante CONASEV y el plazo establecido en la Ley para tales efectos, debiendo tomar las medidas necesarias para la efectiva ejecución de las referidas normas.

Segunda.- De la publicación final

La obligación a que se refiere el numeral 2.3. del artículo $2^{\circ}$ de la Ley se entenderá cumplida con la publicación de un aviso que contenga sólo la indicación del lugar en que se encuentra el listado a que se refiere dicho numeral cuando el costo de las publicaciones con el listado completo supere: 
a) El cincuenta (50\%) por ciento del valor nominal de las acciones cuyos títulos no se han entregado, sin que existan dividendos por pagar;

b) El cincuenta (50\%) por ciento de los dividendos por pagar, sin que existan títulos representativos de acciones por entregar;

c) El cincuenta $(50 \%)$ por ciento del valor nominal de las acciones cuyos títulos no se han entregado y el cincuenta $(50 \%)$ por ciento de los dividendos por pagar.

Tercera.- De los dividendos

El monto de los dividendos no cobrados incluye la reexpresión o reajuste por efectos de la inflación hasta la oportunidad de la publicación a que se refiere el numeral 2.1 del artículo $2^{\circ}$ de la Ley7 o el cierre del ejercicio anterior, según corresponda.

RESOLUCIÓN DEL COMITÉ DE PROTECCIÓN AL ACCIONISTA MINORITARIO No 85-99-EF/94.COPA

Lima, 23 de setiembre de 1999

VISTOS:

El Documento Simple No 99/08193 presentado por Telefónica del Perú S.A.A., en adelante Telefónica, el Oficio $\mathrm{N}^{\circ} 345-99-\mathrm{EF} / 94$.COPA del 27 de julio de 1999, la Resolución $N^{\circ}$ 57-99-EF/94.COPA, el Documento Simple $N^{\circ} 99 / 10201$ y el Oficio $N^{\circ} 367-99-E F / 94 . C O P A$ del 17 de agosto de 1999;

\section{CONSIDERANDO:}

1.- Que Telefónica mediante escrito GGR-131-A-2637-99 del 26 de julio de 1999 solicitó la suspensión de los plazos otorgados para elevar los expedientes de las Quejas interpuestas por accionistas minoritarios de la recurrente, que han sido declarados fundados por el Comité de Protección al Accionista Minoritario de CONASEV, 
en adelante el Comité, mediante Resoluciones $\mathrm{N}^{\circ} 21,22,23,24$, 25, 32, 35, 37, 38, 39, 40, 41-99-EF/94.COPA; asimismo, solicitó audiencia ante el Comité para expresar sus puntos de vista respecto a la elevación de los expedientes;

2.- Que mediante Resolución N 57 -99-EF/94.COPA del 5 de agosto de 1999 se otorgó por equidad la suspensión del plazo fijado en las resoluciones citadas en el considerando precedente y se concedió la audiencia solicitada, la misma que se llevó a cabo en la sesión del Comité de 5 de agosto de 1999, a la cual asistieron la doctora Cristina Pareja Pallarés y el doctor Víctor Carlos Schwartzmann Larco en su condición de Gerente Central Legal y de Regulación y Gerente Legal de Telefónica, respectivamente, quienes desarrollaron extensamente la posición de la sociedad recurrente;

3.- Que mediante informe escrito presentado el 11 de agosto de 1999 , Telefónica reitera que el Comité es competente para supervisar el cumplimiento de la Ley de Protección al Accionista Minoritario, Ley No 26985, sancionar los casos de incumplimiento y solucionar determinadas controversias entre los accionistas y la Sociedad. En opinión de Telefónica, las controversias susceptibles de ser solucionadas por el Comité, de acuerdo a la Ley No 26985, están restringidas a las originadas en la negativa absoluta de la Sociedad de entregar los títulos representativos de acciones reclamados por los accionistas, y no se refieren al reconocimiento a favor de accionistas del derecho a tener más acciones que las registradas a su nombre en la matrícula de acciones, ni a la determinación de indemnizaciones por errores que pudieran haberse producido en los acuerdos de capitalización de aportes;

4.- Que este Comité ha verificado en los expedientes relativos a los reclamaciones interpuestas por accionistas minoritarios de Telefónica, que es práctica usual de ésta la emisión de diversos certificados a nombre de los accionistas que pueden responder, entre otras razones, a aportes de distinto origen o derivados de uno o varios servicios telefónicos, por lo que la afirmación de la Sociedad en el sentido que en muchas de las quejas declaradas fundadas ya existe un certificado a disposición del accionista y se cumple así con la exigencia de la Ley $\mathrm{N}^{\circ} 26985$, no descarta la posibilidad que existan otros certificados o se tenga derecho a la emisión de los mismos cuya entrega es uno de los propósitos expresados en la referida Ley; 
5.- Que en muchos casos los solicitantes reclaman tener derecho a otros certificados o títulos representativos de acciones sin que Telefónica les haya brindado unan respuesta adecuada y oportuna sobre su existencia o inexistencia, no obstante ser quien tiene el control absoluto de la información pertinente;

6.- Que los reclamos respecto de los certificados o títulos representativos de acciones pueden sustentarse en diversas situaciones, tales como: a) referirse a certificados o títulos ya emitidos, incluso amparados en la matrícula de acciones, que se han extraviado o se han entregado a terceros; b) que tratándose de títulos o certificados no emitidos, no se discute el derecho y la Sociedad reconoce la titularidad de las mismas sin entregar el certificado; y, c) que la Sociedad no reconoce más derechos al accionista (negándose por tanto a la entrega de más certificados o títulos representativos de acciones) amparándose para el efecto en su matrícula de acciones o en la caducidad del derecho, produciéndose una discrepancia entre accionista y Sociedad susceptible de ventilarse ante el Poder Judicial o en sede arbitral;

7.- Que en ese sentido, habiéndose establecido que pueden existir uno o más certificados a nombre del accionista, el Comité no considera razonable interpretar que con la entrega de uno o más certificados o títulos representativos de acciones se imposibilite el derecho a reclamar la existencia de mas certificados o títulos representativos de aciones que el accionista minoritario considere pueda corresponderle en discrepancia con la Sociedad;

8.- Que la interpretación contraria implica que el proceso administrativo, diseñado para posibilitar en vía de protección que el accionista minoritario acceda a la tenencia de todos sus certificados o títulos representativos de acciones quede sujeto a un requisito que sólo depende de la emisora: el incumplimiento parcial o total en la entrega de certificados de acciones; lo cual significa negar el acceso a una solución administrativa a quienes recibieron sólo una parte de sus certificados o títulos representativos de acciones;

9.- Que Telefónica, al incumplir con la obligación legal de elevar los expedientes en las quejas que han sido declaradas fundadas, afecta la legalidad misma del procedimiento de protección al accionista minoritario de las sociedades anónimas abiertas de la Ley N$^{\circ} 26985$ 
y su finalidad, por cuanto niega el acceso de los accionistas al mecanismo de solución de controversias que la Ley ha diseñado, hace imposible el conocimiento de la información por parte de ello, y afecta sin duda el derecho a la tutela efectiva y el debido proceso administrativo consagrado en el artículo $139^{\circ}$ inciso 3 ) de la Constitución Política del Perú;

10.- Que Telefónica, en su calidad de administrado, carece de capacidad legal para apartarse del cumplimiento de la ley, con el riesgo de incurrir en la violación del derecho consagrado en el inciso 2) del Artículo $2^{\circ}$ de la Constitución Política del Perú;

11.- Que si Telefónica considera que un determinado reclamo no es competencia del Comité, o no se encuentra en el ámbito de la Ley $\mathrm{N}^{\circ} 26985$, debe igualmente cumplir con elevar el expediente con su opinión, acompañando un informe detallado de los aportes del accionista, las capitalizaciones efectuadas, las acciones a las cuales tiene derecho, su correspondencia o no con la matrícula de acciones, siendo atribución imperativa del Comité evaluar si se configura o no la denegatoria de entrega de certificado o títulos representativos de acciones. Lo contrario implicaría aceptar una interpretación abrogativa de la Ley en beneficio de un interesado, violándose lo dispuesto en los artículos $5^{\circ}, 11^{\circ}, 12^{\circ}$ y siguientes del Texto Único Ordenado de la Ley de Normas Generales de Procedimientos Administrativos;

12.- Que una vez producido el pronunciamiento del Comité, Telefónica puede recurrir y cuestionar la competencia del mismo, o el fondo del pronunciamiento emitido, en la vía contencioso administrativa de acuerdo al inciso 8.1. del artículo $8^{\circ}$ de la Ley $\mathrm{N}^{\circ}$ 26985 y el artículo 148 de la Constitución Política del Perú;

Estando a lo dispuesto en la Ley de Protección a los Accionistas Minoritarios de las Sociedades Anónimas Abiertas, Ley $N^{\circ} 26985$, la Resolución CONASEV No 164-98-EF/94.10 y su modificatoria, así como las Normas Complementarias Procedimentales aprobadas por Resolución CONASEV No 038-99-EF/94.10, y a lo acordado por unanimidad en sesión de Comité de 23 de setiembre de 1999; 
SE RESUELVE:

Artículo $1^{\circ}$.- Dar por concluida la suspensión del plazo establecido en las Resoluciones $N^{\circ} 21,22,23,24,25,32,35,37,38,39,40,41$ 99-EF/94.COPA para el cumplimiento de la obligación legal de Telefónica del Perú S.A.A. de elevar los expedientes cuyas quejas han sido declaradas fundadas, incluyéndose en el presente artículo a las Resoluciones $\mathrm{N}^{\circ}$ 29, 30, 31, 33, 36-99-EF/94.COPA.

Artículo $2^{\circ}$.- Ordenar a la Telefónica del Perú S.A.A. cumpla con elevar los expedientes correspondientes a los Oficios $\mathrm{N}^{\circ} 318,326$, $324,322,328,339,341,343,316,337,302,309,307,305,311$, $313,300-99-E F / 94$.COPA en el plazo de diez (10) días hábiles, contados a partir del día siguiente de su notificación, bajo el apercibimiento señalado en el artículo $9^{\circ}$ de la Ley $\mathrm{N}^{\circ} 26985$.

Artículo $3^{\circ}$.- Notífiquese a la parte interesada, regístrese y cúmplase.

LORENZO ZOLEZZI IBÁRCENA PRESIDENTE

ANÍBAL QUIROGA LEÓN MIEMBRO
JACK BIGIO CHREM

VICEPRESIDENTE

ALONSO MORALES ACOSTA MIEMBRO 